\title{
PENELITIAN SIFAT FISIS DAN MEKANIS BAJA KARBON RENDAH AKIBAT PENGARUH PROSES PENGARBONAN DARI ARANG KAYU JATI
}

\author{
Masyrukan \\ Jurusan Teknik Mesin Universitas Muhammadiyah Surakarta \\ Jl.A. Yani Tromol Pos 1 Pabelan Kartasura \\ masyrukan@ums.ac.id
}

\begin{abstract}
ABSTRAK
Pada penelitian ini, proses pengarbonan (carburising) yang dilakukan adalah dengan menambahkan kandungan unsur karbon (C) ke dalam permukaan baja. Sumber karbon diperoleh dari arang kayu jati yang telah ditumbuk halus. Temperatur yang digunakan selama proses pengarbonan adalah $900^{\circ} \mathrm{C}$, dengan variasi waktu penahanannya 2 jam, 4 jam, dan 6 jam. Setelah itu didinginkan dengan air (quench). Pembuatan benda uji dilakukan untuk mendapatkan sampel dan supaya memudahkan dalam pelaksanaan penelitian. Pengujian yang dilakukan adalah pengujian struktur mikro, pengujian kekerasan dan pengujian impact.Pengujian kekerasan yang telah dilakukan terhadap material pengarbonan menghasilkan distribusi kekerasan dari permukaan menuju inti, untuk masing-masing waktu penahanan yang berbeda. Untuk waktu penahanan 2 jam mulai HVN 257,5 $\mathrm{Kg} / \mathrm{mm}^{2}$ sampai 205,3 $\mathrm{Kg} / \mathrm{mm}^{2}$ menuju inti ; 4 jam mulai $\mathrm{HVN} 273,1 \mathrm{Kg} / \mathrm{mm}^{2}$ sampai $204,4 \mathrm{Kg} / \mathrm{mm}^{2}$ menuju inti ; 6 jam mulai $\mathrm{HVN} 274,6 \mathrm{Kg} / \mathrm{mm}^{2}$ sampai 204,4 Kg/mm menuju inti.Hasil pengamatan foto struktur mikro melalui microscope olympus photomicrographic system dihasilkan foto struktur mikro untuk raw material dan carburising sama terdapat ferit dan perlit, untuk yang dikarburising struktur mikronya, yaitu ferit dan perlit. Semakin lama proses karburising, semakin banyak pula kandungan perlitnya yang mengakibatkan semakin tingginya tingkat kekerasan. Hasil pengujian impak menunjukkan rata-rata harga impak untuk spesimen raw material $=0,350 \mathrm{~J} / \mathrm{mm}^{2}$, waktu penahanan $2 \mathrm{jam}=1,013 \mathrm{~J} / \mathrm{mm}^{2}$, spesimen waktu penahanan $4 \mathrm{jam}=0,600 \mathrm{~J} / \mathrm{mm}^{2}$, spesimen waktu penahanan $6 \mathrm{jam}=1,590 \mathrm{~J} / \mathrm{mm}^{2}$.
\end{abstract}

Kata Kunci : Carburizing, arang kayu jati, baja karbon rendah.

\section{PENDAHULUAN}

Pemakaian logam ferrous baik baja maupun besi cor dengan karakteristik dan sifat yang berbeda membutuhkan adanya suatu penanganan yang tepat sehingga implementasi dari penggunaan logam tersebut dapat sesuai dengan kebutuhan yang ada, khususnya baja. Penggunaan baja karbon rendah banyak digunakan lebih disebabkan karena baja karbon rendah memiliki keuletan tinggi dan mudah dimachining, tetapi kekerasannya rendah dan tidak tahan aus. Baja ini tidak dapat dikeraskan dengan cara konvensional karena kadar karbonnya yang rendah, sehingga dilakukan proses Carburising. Proses Carburising sendiri didefinisikan sebagai suatu proses penambahan kandungan unsur karbon (C) pada permukaan baja. Proses Carburising yang tepat akan menambah kekerasan permukaan sedang pada bagian inti tetap liat. 
Selain dari pada itu ada hal yang perlu diperhatikan sebelum memulai proses pengarbonan (Carburising), yaitu komposisi kimia khususnya perubahan unsur karbon (C) akan dapat mengakibatkan perubahan sifat-sifat mekanik baja tersebut.

\section{TINJAUAN PUSTAKA}

\section{Pengertian Baja Karbon}

Baja merupakan paduan yang terdiri dari unsur utama besi (Fe) dan karbon (C), serta unsur-unsur lain, seperti : $\mathrm{Mn}, \mathrm{Si}, \mathrm{Ni}, \mathrm{Cr}$, $\mathrm{V}$ dan lain sebagainya yang tersusun dalam prosentase yang sangat kecil. Dan unsurunsur tersebut akan berpengaruh terhadap mutu dari baja tersebut.

Pada baja karbon rendah mempunyai kandungan karbon \% C $<0,3 \%$. Sifat kekerasannya relatif rendah, lunak dan keuletannya tinggi. Baja karbon rendah biasanya digunakan dalam bentuk pelat, profil, sekrap, ulir dan baut.

\section{Pengerasan Permukaan Baja (Steel Surface Hardening)}

Pengerasan permukaan dilakukan dengan 2 cara yaitu seluruh permukaan dikeraskan atau sebagian saja dari permukaan yang dikeraskan. Tujuan pengerasan permukaan secara umum adalah memperbaiki ketahanan aus dan ketahanan korosi. Pengerasan permukaan pada baja meliputi dua jenis yaitu Induction Hardening dan Thermo Chemical Treatment.

Prinsip kerja Induction Hardening adalah memanaskan permukaan baja hing-ga temperatur austenit yang sesuai dengan baja yang bersangkutan, kemu-dian disemprotkan pendingin sehingga permukaan menjadi keras.

Prinsip kerja dari Thermo Chemical Treatment adalah menambahkan unsur karbon ke dalam baja untuk mengeraskan bagian permukaan baja tersebut. Salah satu penerapan dari proses Thermo Chemical Treatment adalah carburising (pengarbonan).
Thermo Chemical Treatment dilaku-kan terhadap baja yang mempunyai kadar karbon di bawah 0,3\%. Kadar karbon ini tidak memungkinkan ter-jadinya fasa martensit yang keras.

\section{Carburising}

Pengarbonan(carburising) merupakan suatu proses penambahan kandungan karbon pada permukaan baja untuk mendapatkan sifat baja yang lebih keras pada permukaannya. Kondisi ini sangat diperlukan untuk komponen-komponen yang mensyaratkan tahan aus.

Pada pengarbonan padat, dipakai arang yang dicampur dengan 10\% - 20\% $\mathrm{Na}_{2} \mathrm{CO}_{3}$ / $\mathrm{BaCO}_{3}$, baja dimasukan ke dalam campuran ini, ditempelkan pada suatu wadah dan ditutup rapat kemudian dipanaskan. Dengan demikian permu-kaan baja akan mempunyai kadar karbon yang lebih tinggi.

Kandungan karbon akan bervariasi dalam arah menuju inti. Pada permukaan kandungan karbon tinggi, dan akan berkurang dalam arah menuju inti. Konsekuensinya struktur mikro akan berubah pula dari permukaan menuju inti.

\section{Quenching}

Quench (celup cepat) adalah salah satu perlakuan panas dengan laju pendinginan cepat yang dilakukan dalam suatu media pendingin misal air atau oli. Untuk memperoleh sifat mekanik yang lebih keras. Untuk baja karbon rendah dan baja karbon sedang lazim dilakukan pencelupan dengan air.

Untuk baja karbon tinggi dan baja paduan biasanya digunakan minyak sebagai media pencelupan, pendinginannya tidak secepat air. Tersedia berbagai jenis minyak, seperti minyak mineral dengan kecepatan pendinginan yang berlainan sehingga dapat diperoleh baja dengan berbagai tingkat kekerasan. Untuk pendinginan yang cepat dapat digunakan air garam atau air yang disemprotkan. Beberapa jenis logam dapat 
dikeraskan melalui pendinginan udara terlalu lambat. Benda yang agak besar biasanya dicelup dalam minyak. Suhu media celup harus merata agar dapat dicapai pendinginan yang merata pula. Media pendinginan yang digunakan dalam produksi harus dilengkapi dengan perlengkapan pendinginan.

\section{METODOLOGI PENELITIAN}

Diagram alir pada penelitian ini dibuat agar mudah dalam pelaksanaan penelitian. Adapun diagram alirnya dapat dilihat pada Gambar 1.

\section{Persiapan Benda Uji}

Material yang akan diuji pada penelitian ini adalah baja cor produksi pabrik pengecoran Batur, Ceper, Klaten. Sedangkan banyaknya benda uji adalah 8 buah, yaitu 3 untuk uji kekerasan dan sekaligus untuk uji struktur mikro, dan 1 adalah raw material untuk uji kekerasan dan sekaligus juga untuk uji struktur mikro, 3 yang lain untuk uji impact sedangkan yang 1 untuk raw material uji impact.

\section{Pemotongan}

Pemotongan benda uji ini dilakukan dengan menggunakan gergaji yang dibilasi dengan air .

\section{Karbonasi}

Karbonasi dilakukan pada dapur pemanas (oven). Karbonasi ini menjadi penelitian karena yang akan diuji adalah pengaruh karbonasi terhadap baja karbon rendah.

Pada pengujian ini sistim yang karbonasi dipakai adalah pack karburizing atau pengkarbonan dengan media padat. Sedangkan bahan yang dipakai adalah arang kayu jati.

Mula-mula benda dipanaskan dalam tungku (oven) dengan suhu pemanas $900{ }^{0} \mathrm{C}$, sedangkan lama pemanasan 2, 4, dan 6 jam.
Setelah benda uji selesai dipanaskan dengan sistim karbonasi kemudian didinginkan dengan dicelup pada media pendingin yaitu air.

Peletakan material benda uji ke dalam wadah dari tanah liat selama proses pengarbonan seperti terlihat pada gambar berikut ini.

Pada tahap ini benda uji dihaluskan dengan ampelas untuk menghasilkan permukaan yang rata. Amplas yang digunakan dari nomor 600, 800, 1000, dan untuk mendapatkan hasil permukaan yang halus dan mengkilap benda uji kemudian dipoles dengan menggunakan autosol untuk menghilangkan goresan-goresan yang diakibatkan oleh amplas

Setelah benda uji cukup halus, maka langkah selanjutnya adalah memoles dengan autosol untuk mendapatkan permukaan yang halus dan mengkilat, sehingga struktur benda uji menjadi jelas. Pemolesan dilakukan sebelum pengujian kekerasan setelah benda dipoles dapat langsung diuji.

Pemolesan autosol pada benda uji harus menggunakan kain yang lembut agar permukaan benda benar-benar mengkilat dan tidak ada goresan, karena apabila ada goresan pada permukaan benda uji, maka goresan akan nyata sekali bila dilihat dibawah mikroskop.

\section{Pengetsaan}

Pengetsaan hanya dilakukan untuk benda uji yang akan diamati struktur mikronya. Bahan etsa menggunakan $\mathrm{HNO}_{3}$ (nitrit acid). Tujuannya untuk menampakkan struktur mikro di bawah mikroskop agar tampak jelas.

\section{Pengujian Struktur Mikro}

Alat uji yang digunakan dalam proses ini adalah mikroskop (Olympus Metallurgica Microscope) yang mempunyai perbesaran 100X, 200X, 500X, 1000X, dan 2500X, sedangkan pemotretan struktur mikronya menggunakan alat Olympus Photomicrographic System, dengan perbesaran yang diam-bil $500 \mathrm{X}$. 


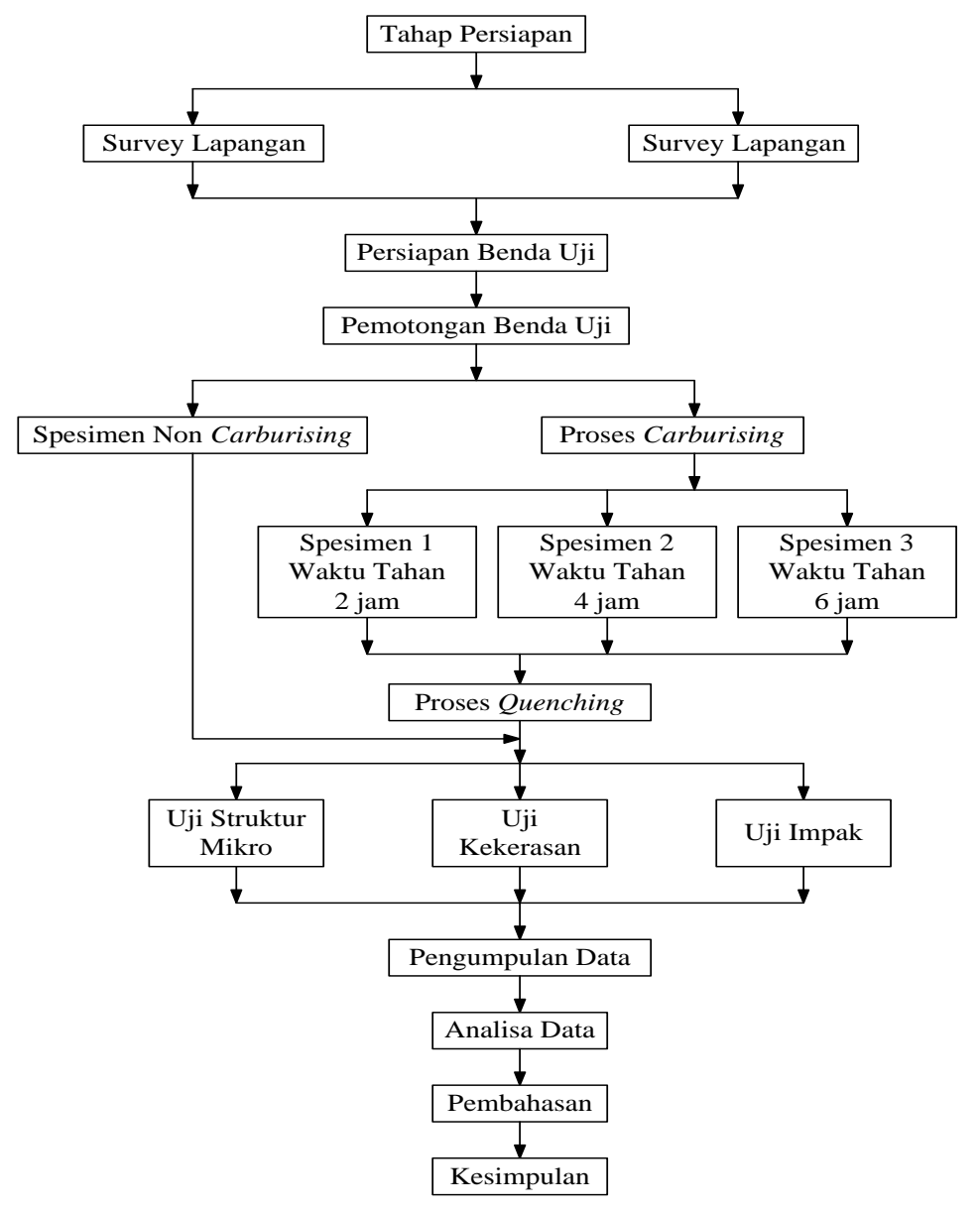

\section{Gambar 1. Diagram alir penelitian}

\section{Pengujian Kekerasan}

Alat yang digunakan dalam pengujian kekerasan adalah Olympus Micro Harde-nenss Tester. Metode pengujian kekerasan dalam pengujian ini adalah menggunakan metode vikers dengan menggunakan pene-trator piramida $136^{\circ}$ dengan beban 200 gr dan waktu tahan pembebanan 5 detik. Pengujian dilakukan sebanyak 5 kali setiap benda uji untuk menentukan kekerasan rata-ratanya.

\section{Pengujian Impact}

Pengujian ini bertujuan untuk mengetahui ketangguhan suatu spesimen terhadap beban patah. Hal yang sangat penting pada uji impact ini adalah pembuatan takik yang memerlukan ketelitian khusus dan kepresisan yang tinggi. Pengujian ini dilakukan untuk membanding-kan dua benda uji yaitu baja karbon rendah sebelum dikarbonasi dan baja karbon rendah setelah dikarbonasi. Jadi spesimen uji dibuat sedemikian rupa sehingga kedua benda uji benar-benar memiliki dimensi yang sama. Pengujian ini menggunakan mesin Charpy Impact Machine.

\section{HASIL DAN PEMBAHASAN}

Pembahasan hasil pengujian struktur mikro

Dari hasil pengamatan struktur mikro sebelum dikarburising menunjukkan struktur ferit lebih banyak, akan tetapi sesudah proses karburising justru struktur perlitnya yang lebih banyak daripada feritnya. Gambar Pengujian dapat dilihat pada gambar 2 sampai gambar 5. 


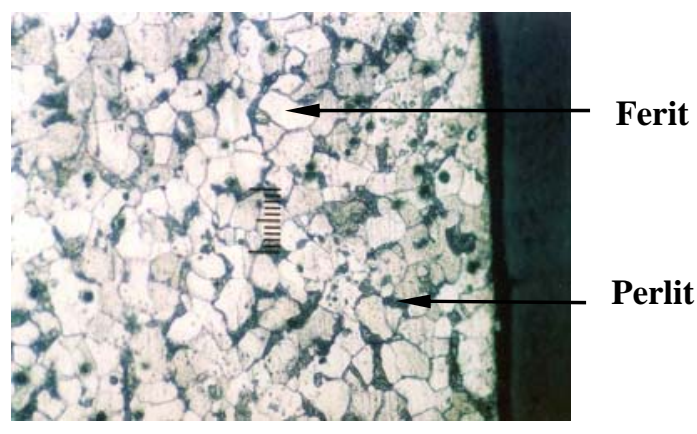

Gambar 2. Foto struktur mikro raw material

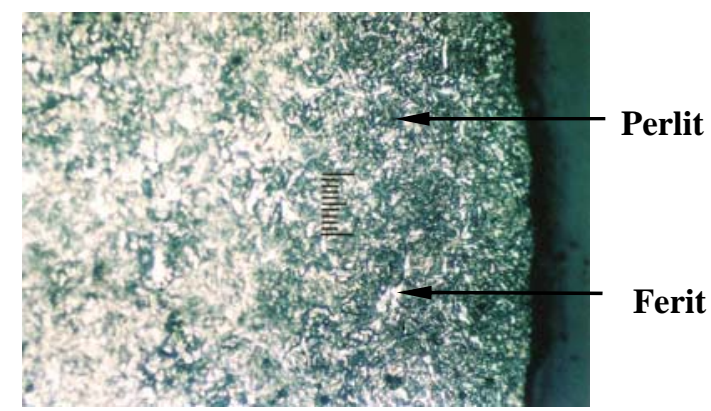

Gambar 4. Foto struktur mikro material pengarbonan

\section{Pembahasan hasil pengujian kekerasan}

Dari proses pengujian kekerasan pada 4 spesimen terdapat perbedaan keke-rasan, yaitu pada karburising selama 6 jam dengan harga kekerasan tertinggi $(274,6 \mathrm{~kg} / \mathrm{mm}$ ) disusul dengan karbu-rising selama 4 jam $\left(273,1 \mathrm{~kg} / \mathrm{mm}^{2}\right)$ dan karburising selama 2

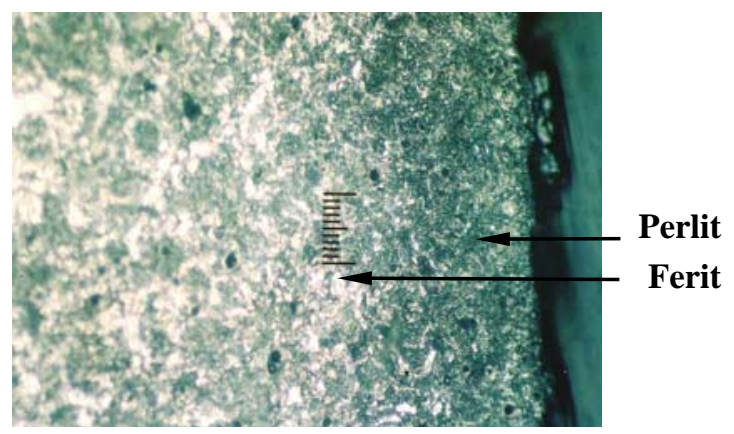

\section{Gambar 3. Foto struktur mikro materialpengarbonan waktu}

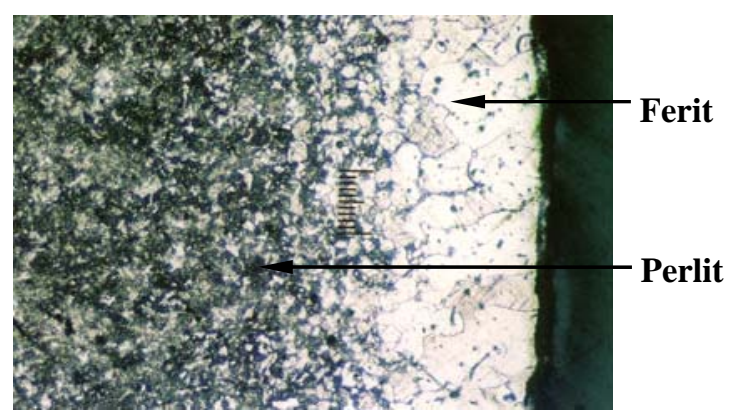

Gambar 5. Foto struktur mikro material pengarbonan waktu tahan 6

jam $\left(257,5 \mathrm{~kg} / \mathrm{mm}^{2}\right)$ serta raw material dengan harga kekerasan $\left(214,3 \mathrm{~kg} / \mathrm{mm}^{2}\right)$. Hasil selengkapnya dapat dilihat pada gambar6.

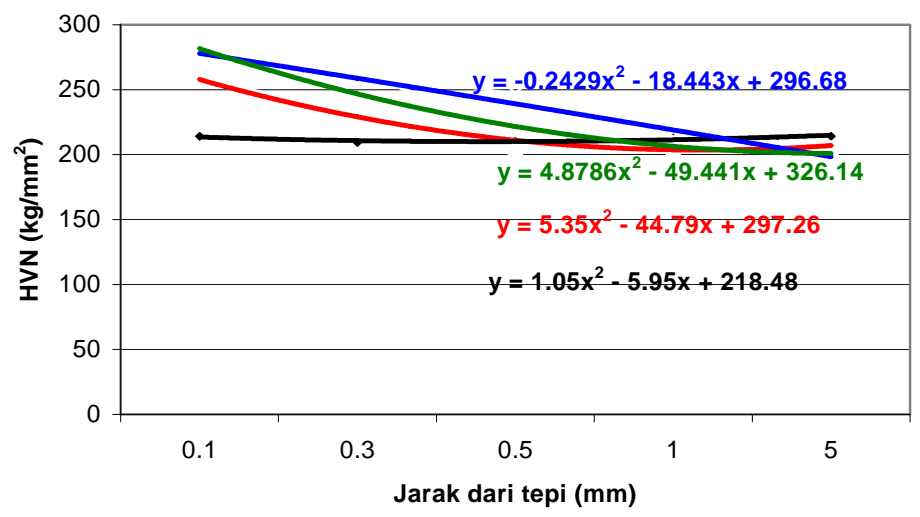

- Poly. (Waktu tahan 2 jam) - Poly. (Raw material)
Poly. (Waktu tahan 6 jam) - Poly. (Waktu tahan 4 jam)

Gambar 6. Grafik hasil pengujian kekerasan material pengarbonan 


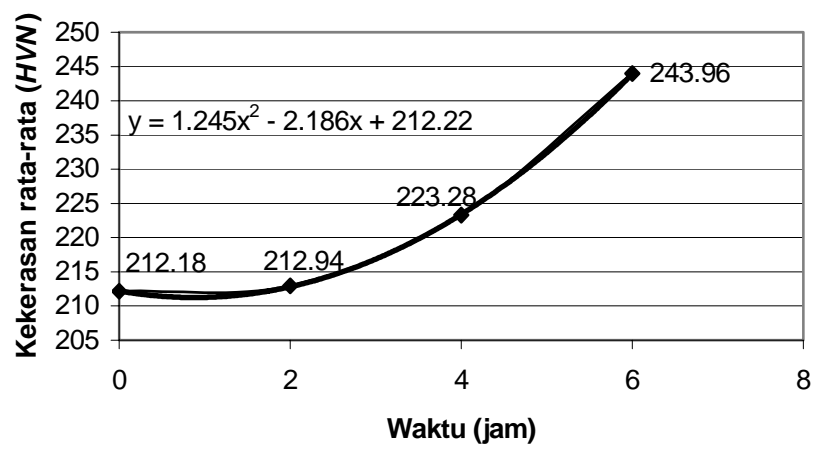

Gambar 7. Grafik hasil pengujian kedalaman difusi material pengarbonan

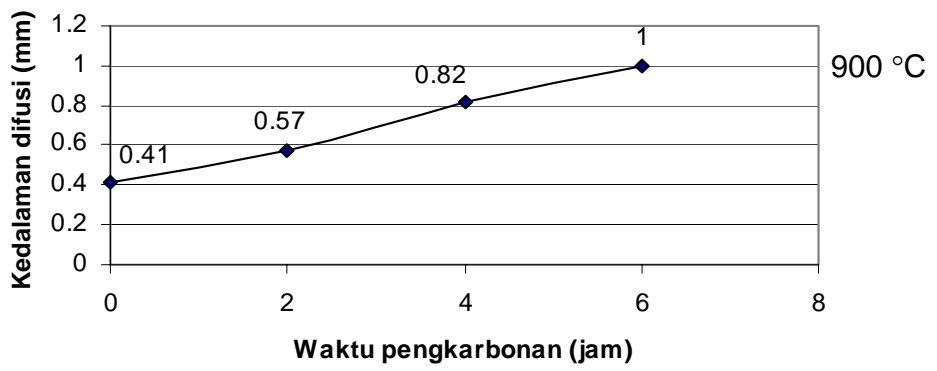

Gambar 9. Grafik hasil difusi pengarbonan

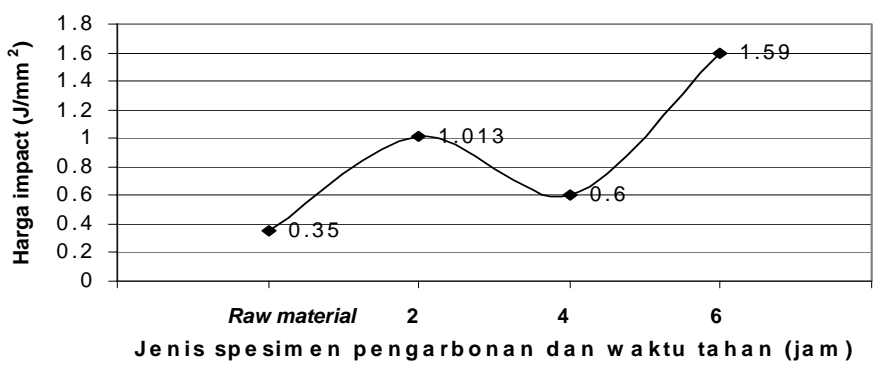

Gambar 10. Grafik harga impact spesimen pengarbonan dengan waktu tahan

\section{Pembahasan hasil pengujian impact}

Dari pengujian impact pada baja karbon rendah yang sebelum dikarbonasi diperoleh harga keuletan rata-rata sebesar 0,350 Joule/mm , sedangkan pa-da baja setelah dikarbonasi harga keulet-an rata-ratanya sebesar 1,067 Joule/mm ${ }^{2}$ kenaikan harga impact pada baja sesudah dikarbonasi dipengaruhi oleh perubahan kekerasan. Hal tersebut akan mempenga-ruhi harga keuletannya. Hasil pengujian impact selengkapnya dapat dilihat pada gambar 9.

\section{KESIMPULAN}

Berdasarkan hasil data penelitian dan hasil analisa serta pembahasan yang didapat, maka dapat disimpulkan sebagai berikut :

Berdasarkan data dan grafik hasil pengujian kekerasan pada baja karbon rendah terdapat perubahan kekerasan, yaitu pada raw material $(212,18 \mathrm{~kg} / \mathrm{mm})$, kekerasannya naik pada proses karbu-rising 2 jam menjadi (257,5 kg/mm ), karburising 4 jam $(273,1 \mathrm{~kg} / \mathrm{mm})$ dan karburising 6 jam har- 
ga kekerasannya tertinggi $\left(274,6 \mathrm{~kg} / \mathrm{mm}^{2}\right)$.

Hasil pengamatan foto struktur mikro melalui microscope olympus photomicrographic system dihasilkan foto struktur mikro untuk raw material dan karburising sama terdapat ferit dan perlit, untuk yang dikarburising struktur mikronya, yaitu ferit yang berwarna putih, dan untuk perlit berwarna hitam. Semakin lama proses karburising, semakin banyak pula kandungan perlitnya yang mengakibatkan semakin tingginya tingkat kekerasan.
Dari pengujian impact pada baja karbon rendah yang sebelum dikarbonasi diperoleh harga keuletan rata-rata sebesar 0,350 Joule/mm , sedangkan pada baja setelah dikarbonasi harga keuletan rata-ratanya sebesar 1,067 Joule/mm ${ }^{2}$ kenaikan harga impact pada baja sesudah dikarbonasi dipengaruhi oleh perubahan kekerasan. Hal tersebut mempengaruhi harga keuletannya.

\section{DAFTAR PUSTAKA}

Darmawan, A. S., 2001, Bahan Kuliah Pemilihan Bahan dan Proses, UMS, Surakarta.

George Zainal Haddy, 1992, Pengetahuan Tentang Bahan Peleburan, YDBA \& BBLM.

Sudihono, 1995, Teknologi Besi Tuang Kelabu, Politeknik Manifakturing ITB, Bandung.

Surdia T., Chijiwa, K., 1991, Teknik Pengecoran Logam ,cetakan keenam, Pradnya Paramita, Jakarta.

Vliet, G.L, J. Van, 1984, Teknologi untuk Bangunan Mesin Bahan-bahan I, Erlangga, Jakarta. 
